\title{
Improvement in the Forecasting of Heavy Rainfall over South China in the DSAEF_LTP Model by Introducing the Intensity of the Tropical Cyclone
}

\author{
DING CHENCHEN \\ Key Laboratory of Meteorological Disaster, Ministry of Education (KLME), Nanjing University of Information Science and \\ Technology, Nanjing, and State Key Laboratory of Severe Weather, Chinese Academy of Meteorological Sciences, \\ China Meteorological Administration, Beijing, China \\ FUMIN REN \\ State Key Laboratory of Severe Weather, Chinese Academy of Meteorological Sciences, \\ China Meteorological Administration, Beijing, China \\ YANAN LIU \\ Institute of Atmospheric Physics, Chinese Academy of Sciences, Beijing, China \\ JOHN L. MCBRIDE \\ School of Earth Science, University of Melbourne, and Research and Development Division, \\ Bureau of Meteorology, Melbourne, Australia \\ TIAN FENG \\ State Key Laboratory of Severe Weather, Chinese Academy of Meteorological Sciences, \\ China Meteorological Administration, Beijing, and Chengdu University of Information Technology, \\ Chengdu, China
}

(Manuscript received 12 December 2019, in final form 7 June 2020)

\begin{abstract}
The intensity of the tropical cyclone has been introduced into the Dynamical-Statistical-Analog Ensemble Forecast (DSAEF) for Landfalling Typhoon (or tropical cyclone) Precipitation (DSAEF_LTP) model. Moreover, the accumulated precipitation prediction experiments have been conducted on 21 target tropical cyclones with daily precipitation $\geq 100 \mathrm{~mm}$ in South China from 2012 to 2016 . The best forecasting scheme for the DSAEF_LTP model is identified, and the performance of the prediction is compared with three numerical weather prediction models (the European Centre for Medium-Range Weather Forecasts, the Global Forecast System, and T639). The forecasting ability of the DSAEF_LTP model for heavy rainfall (accumulated precipitation $\geq 250$ and $\geq 100 \mathrm{~mm}$ ) improves when the intensity of the tropical cyclone is introduced, giving some advantages over the three numerical weather prediction models. The selection of analog tropical cyclones with a maximum intensity (during precipitation over land) equaling to or higher than the initial intensity of the target tropical cyclone gives better forecasts. The prediction accuracy for accumulated precipitation is higher for tropical cyclones with higher intensity and higher observed precipitation, with in both cases positive linear correlations with the threat score.
\end{abstract}

\section{Introduction}

Tropical cyclones (TCs) are frequent events and can cause large numbers of casualties (Zhang et al. 2009; Chen 2010), mainly as a result of heavy rainfall (Rappaport

Corresponding author: Dr Fumin Ren, fmren@163.com
2000; Zhang et al. 2010). In 1975, the maximum daily precipitation of Typhoon Nina in Henan Province of China reached $1062 \mathrm{~mm}$, resulting in damage to six large- and medium-sized reservoirs and at least 26000 deaths (Chen and $\mathrm{Xu}$ 2017). In the United States, Hurricane Harvey (2017) after landfall produced 5-day accumulated rainfall totals exceeding $1000 \mathrm{~mm}$ across 
a wide swath of the Houston metropolitan area in the state of Texas. There were 70 deaths and an estimated $\$ 125$ billion (U.S. dollars) economic damage (Emanuel 2017; Klotzbach et al. 2018).Prediction of the heavy rainfall caused by TCs is therefore crucial in disaster prevention and mitigation and is a significant area of scientific research (Chen et al. 2010).

There has been much research on understanding the formation of heavy precipitation in TCs. There are many factors involved that can be characterized as the underlying surface variables, the ambient variables and the variables specific to TCs (Lonfat et al. 2004). Considering the first of these, the movements of TCs over different underlying surfaces (e.g., mountains, coastlines, lakes, and wetlands) have important effects on the intensity and asymmetrical distribution of precipitation (Wu 2001; Shen et al. 2002; Xu et al. 2014; Meng and Wang 2016). Concerning ambient variables, the intensity and range of the precipitation from TCs generally vary with the environmental conditions, e.g., the injection of cold air, the transport of water vapor, and the vertical wind shear. This variation is dependent on whether the TC can obtain more favorable dynamic environmental conditions including ambient water vapor, energy, and vorticity when interacting with the ambient field during landfall (DiMego and Bosart 1982; Chan et al. 2004; Liu et al. 2007; Dong et al. 2009; Lin et al. 2016).

Changes in the variables specific to TCs also have large effects on rainfall. The track, landfall date, intensity, and structure of the TC also affect the intensity and distribution of precipitation (Marchok et al. 2007; Xie and Zhang. 2012; Wu et al. 2013; Yu et al. 2015; Jiang et al. 2018; Qiu et al. 2019). Studies of the speed and direction of the TC movement have shown that the front quadrant of the moving direction is prone to intense precipitation (Chen et al. 2006; Cecil 2007). Considering TC intensity, the distribution and variation of TC precipitation are closely related to intensity and its change (Kieper and Jiang 2012; Jiang and Ramirez 2013; Zagrodnik and Jiang 2014; Alvey et al. 2015; Harnos and Nesbitt 2016). Lonfat et al. (2004) analyzed the TCs of different intensity categories and found that the mean maximum TC precipitation was in the front quadrant but varied with the intensity of TCs. Moreover, the TC peak mean axisymmetric rain rates increase with increasing intensity of the TC. Barnes and Barnes (2014) found that with the increase of TC intensity, the radius of the eye decreased while the eyewall area and rain rate increased. Yu et al. (2017) analyzed 133 TCs in China and found that the axisymmetric distribution of TC rainfall is closely related to intensity. Stronger TCs always have larger axisymmetric total rain and a lager rain area.
Various methods have been proposed to forecast the precipitation from TCs. These include statistical prediction models, numerical weather prediction (NWP) by dynamical models and dynamic-statistical methods. For statistical methods, extrapolation, stepwise regression and principal component analysis are applied for quantitative precipitation prediction (Wei 2012; Li et al. 2015; Huang et al. 2018). As the skill of numerical weather prediction has increased over the decades, statistical methods have generally been replaced by NWP models, which in most countries form the basis of TC rainfall prediction in the operational forecast and warning centers. However, due to the complexity of the mechanisms for production of heavy rainfall, the current operational forecasting capability is still limited (Tuleya et al. 2007; Marchok et al. 2007; Wang et al. 2012; Gao et al. 2013).

In order improve TC precipitation forecasts with a new method, Ren et al. (2018) developed an objective TC track similarity area index (TSAI) for the selection of analog TCs from the historic database. Prediction experiments for the accumulated precipitation of TCs over South China have shown that the forecasting of heavy precipitation by the TSAI is comparable with the NWP models. Recently, Ren et al. (2020) proposed a Dynamical-Statistical-Analog Ensemble Forecast (DSAEF) Model for Landfalling Typhoon (or TC) Precipitation (the DSAEF_LTP model). This model introduces two physical variables (the TC track and landfall date) into the DSAEF_LTP model. The results of experiments to forecast accumulated precipitation show that the use of more physical variables improves the accuracy of the generalized initial value and the forecasting ability of the DSAEF_LTP model. In this article, a third variable is added to the selection, the TC intensity (wind speed). The paper documents the method for introducing the third variable and compares the predictive skill with that of the two-variable model.

Section 2 introduces the data and methodology. Section 3 describes the introduction of the intensity of the TC to the model and the design of the accumulated precipitation prediction experiment. Section 4 compares and analyzes the prediction results for the DSAEF_LTP model before and after the introduction of the intensity of the TC. The last section gives our conclusions.

\section{Data and methodology}

\section{a. Data}

Historical observed daily precipitation data (12001200 UTC) from 190 rain gauge stations in South China are obtained from the National Meteorological Information Center of China Meteorological Administration (CMA) for the time period 1960-2017 (Fig. 1). In this study, the 


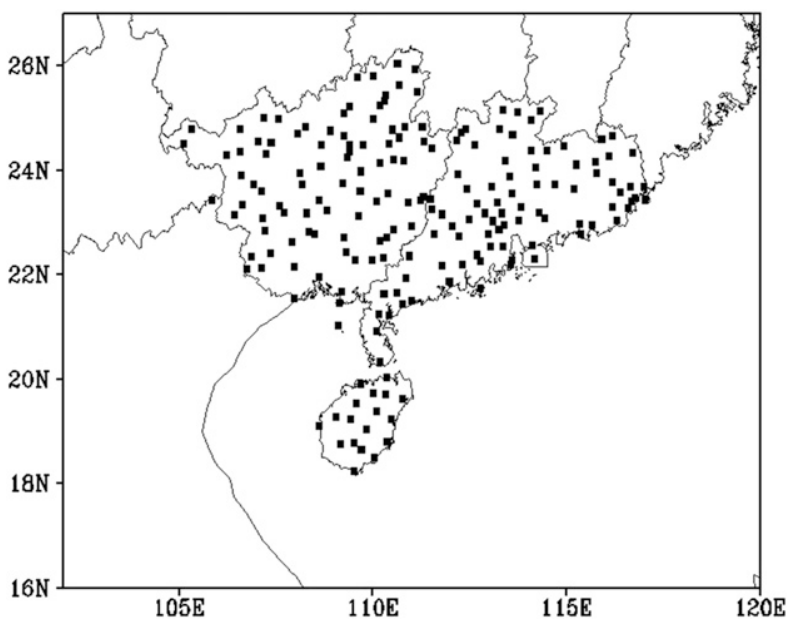

FIG. 1. Distribution of the 190 rain gauge stations in South China.

accumulated precipitation refers to the sum of TC precipitation within the life of a TC for each station.

Historical data (track, time, and wind) for TCs are obtained from the best track dataset (6-h intervals) of the CMA's TC database (http://tcdata.typhoon.org.cn/ zjljsji_zlhq.html) for the time period 1960-2017 and are used to find the analog tracks. The observed and predicted information (track, time, and wind) of the target TCs are obtained from real-time operational forecast data based on the revised NWP model issued by the CMA National Meteorological Center (NMC).

The grid precipitation forecast data of three NWP models are used to evaluate the performance of the DSAEF_LTP model for the time period 2012-16: 1) the European Centre for Medium-Range Weather Forecasts (ECMWF) model; 2) the Global Forecast System (GFS) of the U.S. National Centers for Environmental Prediction; and 3) T639, the global spectral model of the CMA/NMC. The equivalent horizontal resolution of the three NWP models is $0.25^{\circ} \times 0.25^{\circ}, 1^{\circ} \times 1^{\circ}$, and $1.125^{\circ} \times 1.125^{\circ}$, respectively. To compare with the precipitation data from rain gauge stations, the daily precipitation data from the NWP models are interpolated to the rain gauge stations by the method of inverse-distance weighting ( $\mathrm{Lu}$ and Wong 2008). The component of the NWP forecast that is associated with the TC is identified by the objective synoptic analysis technique (OSAT) (Ren et al. 2001, 2007).

\section{b. Methodology}

\section{1) THE OBJECTIVE SYNOPTIC ANALYSIS TECHNIQUE (OSAT)}

The OSAT (Ren et al. 2001, 2007), has the purpose of partitioning TC precipitation from daily data and has been widely applied (Ren et al. 2002, 2006; Chang et al.
2012; Luo et al. 2016; Jiang et al. 2018; Qiu et al. 2019). This technique consists of four steps: 1) identification of the natural rainband;2) discrimination of the potential TC rainband; 3 ) discrimination of each station; and 4) combination of the complete TC rainband.

\section{2) TRACK SIMILARITY AREA INDEX (TSAI)}

The TSAI (Ren et al. 2018) is an objective technique to select the analog track from historic TC data. The principle of TSAI is to calculate the area enclosed by the two tracks, the historical TC and that of the target TC. The smaller the area, the higher the similarity.

3) DYNAMiCAL-STATISTICAL-ANALOG ENSEMBLE FORECAST FOR LANDFALLING TYPHOON MODEL

Ren et al. (2020) developed the DSAEF model and applied this to the prediction of precipitation from TCs that made landfall. This study uses the DSAEF_LTP model (Landfalling TC Prediction model) to predict the accumulated precipitation for target TCs. Application of the model consists of four steps: 1) obtain a forecast of the TC track using operational forecast data from the CMA/NMC; 2) construct the generalized initial value (GIV), including the variables specific to the TC and the ambient variables; 3 ) identify analogs, based on the two or three variables used to define the GIV, in this case the track similarity identified by the TSAI, the landfall date similarity identification, and the intensity similarity; and 4) find the ensemble LTP of the analog cyclone using the accumulated precipitation obtained by OSAT from similar historical TCs to forecast the future precipitation of the target TC.

\section{4) THREAT SCORE}

The threat score (TS) is the primary operational forecast verification metric used in China for the operational prediction of precipitation. The formula is

$$
\mathrm{TS}=\frac{\text { hits }}{\text { hits }+ \text { misses }+ \text { false alarms }} .
$$

The meanings of the terms in the formula are as follows. "Hits" indicate the number of rain gauge stations that both observed precipitation and predicted precipitation are within the same specified threshold range. "Misses" mean the number of rain gauge stations that the observed precipitation is within the specified threshold, while the predicted precipitation is not. "False alarms" represent the number of rain gauge stations that the predicted precipitation is within a specified threshold and the observed precipitation is not (Table 1 of McBride and Ebert 2000). 
TABLE 1. Combination of values for the intensity of tropical cyclones.

\begin{tabular}{lcccc}
\hline \hline & \multicolumn{4}{c}{ Four categories } \\
\cline { 2 - 5 } \multicolumn{1}{c}{ Five levels } & $\begin{array}{c}\text { Avg intensity on first } \\
\text { rainy day }\end{array}$ & $\begin{array}{c}\text { Max intensity on first } \\
\text { rainy day }\end{array}$ & $\begin{array}{c}\text { Avg intensity on all } \\
\text { rainy days }\end{array}$ & $\begin{array}{c}\text { Max intensity on all } \\
\text { rainy days }\end{array}$ \\
\hline $\begin{array}{l}\text { All grades (grade 1 tropical depression } \\
\text { to grade 6 supertyphoon) }\end{array}$ & $(1,1)$ & $(2,1)$ & $(3,1)$ & $(4,1)$ \\
Same grade and above & $(1,2)$ & $(2,2)$ & $(3,2)$ & $(4,2)$ \\
Same grade and below & $(1,3)$ & $(2,3)$ & $(3,3)$ & $(4,3)$ \\
Same grade only & $(1,4)$ & $(2,4)$ & $(3,4)$ & $(4,4)$ \\
Same grade or one-grade difference & $(1,5)$ & $(2,5)$ & $(3,5)$ & $(4,5)$ \\
\hline
\end{tabular}

\section{5) BIAS SCORE}

In this study, besides the hit score, we use the bias score (BS). The formula is

$$
\mathrm{BS}=\frac{\text { hits }+ \text { false alarms }}{\text { hits }+ \text { misses }} .
$$

The meanings of the terms in the formula are the same as those in the formula of threat score. When the number of false alarms equals to that of misses, which means the two "areas" are equivalent, the value of bias score is 1 . Meanwhile, if the area (number) of false alarms is greater (less) than that of misses, the value is greater (less) than 1 . Thus, in the context of this paper the bias for each individual accumulated precipitation forecast, the bias score is a useful measure of the accuracy of the areal extent of TC rainfall above a given threshold.

\section{TC intensity and experimental design}

\section{a. TC intensity}

There are two steps in introducing a new variable into the DSAEF_LTP model. First, a suitable measure for the new variable should be chosen. We use wind speed (the 2-min average maximum wind speed at $10-\mathrm{m}$ height near the center of the TC) to represent the intensity of the TC. Second, an index needs to be defined to be used as a basis for similarity between target and historic TCs in the process of choosing analogs. The intensity of the $\mathrm{TC}$ is divided into categories and levels. There are four categories and five levels, giving a total of 20 combinations (Table 1). The four categories are the average and maximum intensity on the first rainy day (the first day that the TC produces rain over land) and all rainy days (the whole process of TC rainfall over land). The intensity of the TC is divided into six grades: tropical depression $\left(10.8-17.1 \mathrm{~m} \mathrm{~s}^{-1}\right)$, tropical storm $\left(17.2-24.4 \mathrm{~m} \mathrm{~s}^{-1}\right)$, severe tropical storm (STS; 24.5-32.6 $\mathrm{m} \mathrm{s}^{-1}$ ), typhoon (32.7$41.4 \mathrm{~m} \mathrm{~s}^{-1}$ ), severe typhoon (STY; 41.5-50.9 $\mathrm{m} \mathrm{s}^{-1}$ ), and supertyphoon (superTY; $\geq 51 \mathrm{~m} \mathrm{~s}^{-1}$ ). The five levels are the differences in intensity between the target TC and the historical TC, including all grades (no limitation), the same grade and above (intensities of historical TCs that are greater than or equal to the target TC), the same grade and below, only the same grade, and the same grade or one-grade difference.

Table 2 lists the eight parameters of the DSAEF_LTP model of TC intensity. The eight parameters combinations give a total of 2160000 sets of forecasting schemes for the ideal state of a single target TC.

\section{b. Experimental design}

We conduct accumulated precipitation forecasting experiments using the DSAEF_LTP-2 and DSAEF_LTP-3 models to examine the changes in forecasting ability. The DSAEF_LTP-2 and DSAEF_LTP-3 models represent the DSAEF_LTP model with two (no intensity) and three (with intensity) variables, respectively. The time period 2012-16 is selected as the experimental period according to the retained historical data to compare the results of the three NWP models (ECMWF, GFS and T639). We select historical TCs with daily precipitation $\geq 100 \mathrm{~mm}$ (at least one rain gauge station) in South China (Fig. 1) during 2012-16 as the target TCs in the experiment.

In total, 21 target TCs (Table 3), 13 of which occurred during 2012-14, are used as training samples to choose the optimum set of parameters for the DSAEF_LTP model. The remaining eight TCs occurring during 201516 are used as independent samples to validate the model. After conducting the training samples experiment, the schemes of the thirteen TCs that can be performed jointly are selected as the conventional schemes. Considering the performance of DSAEF_LTP model in forecasting heavy precipitation ( $\geq 250$ and $\geq 100 \mathrm{~mm}$ ) (Ren et al. 2020), the average threat score of multiple TCs below two heavy precipitation thresholds for each conventional scheme was calculated in the training experiment. The best forecasting scheme of the DSAEF_LTP model is the one in which the sum of TS250 (the threat score of accumulated precipitation $\geq 250 \mathrm{~mm}$ ) and 
TABLE 2. Parameters of the DSAEF_LTP-3 model and the values for the best forecasting scheme.

\begin{tabular}{|c|c|c|}
\hline Parameters $(1-8)$ & Tested values & Optimized values \\
\hline Initial time $(\mathrm{P} 1)$ & $\begin{array}{l}\text { 1-4 for } 1200 \text { and } 0000 \text { UTC on the day of the tropical cyclone } \\
\text { precipitation occurring on land and the day before, } \\
\text { respectively }\end{array}$ & $\mathrm{P} 1=1$ \\
\hline Similarity region $(\mathrm{P} 2)$ & $\begin{array}{l}\text { A parameter of TSAI defined as a rectangle with the diagonal } \\
\text { points A and B. A is the tropical cyclone locations at } 0,12,24 \text {, } \\
36 \text {, or } 48 \mathrm{~h} \text { prior to the initial time, and B is the tropical } \\
\text { cyclone locations at } 0,6 \text {, or } 12 \mathrm{~h} \text { prior to the maximum lead } \\
\text { time. The lead time refers to the time interval between the } \\
\text { time point of the NWP model's prediction with the NWP } \\
\text { model's lead time and the initial time. } 1-15\end{array}$ & $\begin{array}{l}\mathrm{P} 2=12(12 \mathrm{~h} \text { before the initial } \\
\text { time and } 12 \mathrm{~h} \text { before the } \\
\text { maximum lead time })\end{array}$ \\
\hline $\begin{array}{l}\text { Threshold of the segmentation ratio of } \\
\text { a latitude extreme point (P3) }\end{array}$ & $\begin{array}{l}\text { A parameter of TSAI defined as } 1-3 \text { for } 0.1,0.2 \text { and } 0.3 \text {, } \\
\text { respectively }\end{array}$ & $\mathrm{P} 3=3$ \\
\hline $\begin{array}{l}\text { Overlapping percentage threshold of } \\
\text { two tropical cyclone tracks }(\mathrm{P} 4)\end{array}$ & $\begin{array}{l}\text { A parameter of TSAI defined as } 1-6 \text { for } 0.4,0.5,0.6,0.7,0.8 \text {, } \\
\text { and } 0.9, \text { respectively }\end{array}$ & $P 4=6$ \\
\hline Seasonal similarity (P5) & $\begin{array}{l}\text { 1-5 for the whole year, May-November, July-September, the } \\
\text { same landfall month as the target tropical cyclone and within } \\
15 \text { days of the target tropical cyclone landfall time, } \\
\text { respectively }\end{array}$ & $\mathrm{P} 5=2$ \\
\hline Intensity similarity $(\mathrm{P} 6)$ & Four categories, as in Table 1 and five levels, as in Table 1 & $\mathrm{P} 6=($ category, level $)=(4,2)$ \\
\hline $\begin{array}{l}\text { Number }(N) \text { of tropical cyclones with } \\
\text { the top } N \text { closest track } \\
\text { similarity (P7) }\end{array}$ & $1-10$ for $1,2, \ldots$, and 10 , respectively & $\mathrm{P} 7=2$ \\
\hline Ensemble forecast scheme (P8) & 1-2 for mean, maximum, respectively & $\mathrm{P} 8=2$ \\
\hline Total No. of schemes & $4 \times 15 \times 3 \times 6 \times 5 \times 4 \times 5 \times 10 \times 2=2160000$ & \\
\hline
\end{tabular}

TS100 (the threat score of accumulated precipitation $\geq$ $100 \mathrm{~mm}$ ) is the largest in the conventional schemes. The independent samples experiment is then carried out to evaluate the performance of the best forecasting scheme. The prediction performances of different models (DSAEF_LTP-2, DSAEF_LTP-3, and the three NWP models) are compared and the performance of the DSAEF_LTP-3 model is analyzed further.

\section{Results}

The best forecasting scheme of the DSAEF_LTP model is obtained through the training samples experiment. Due to some changes in parameter definition (the tested value of the initial time) and an update of the historic track data (the target TCs), the results of the DSAEF_LTP-2 model vary from the results presented in Ren et al. (2020). Figure 2 shows the scatterplots of the average threat score for the training samples experiments for the DSAEF_LTP-2 and DSAEF_LTP-3 models. The horizontal (vertical) coordinate is the average threat score value of accumulated precipitation $\geq$ $250 \mathrm{~mm}(\geq 100 \mathrm{~mm})$. As discussed by Ren et al. (2020) the inclusion of short track TC's limits the range of values of parameters $\mathrm{P} 1$ and $\mathrm{P} 2$, leading to a sharp decrease in the total number of forecasting schemes in the experiment (Ren et al. 2020). There are 4890 (Fig. 2a) and 48340 (Fig. 2b) conventional schemes (blue dots) in which all target TCs can be run using both the DSAEF_LTP-2 and DSAEF_LTP-3 models. For the three NWP models the best performance for forecasting accumulated precipitation $\geq 250 \mathrm{~mm}$ is T639 (threat score 0.042 ), while for precipitation $\geq 100 \mathrm{~mm}$ is ECMWF (threat score 0.1726). Most of the schemes of the DSAEF_LTP-2 (1552 schemes) and DSAEF_LTP-3 (14206 schemes) models perform better than the ECMWF and T639 models in the upper-right quadrant enclosed by the two inner dashed axes. The red dots in Fig. 2 are the best forecasting schemes of the DSAEF_LTP-2 and DSAEF_LTP-3 models. The coordinates of the red dots in Figs. $2 \mathrm{a}$ and $2 \mathrm{~b}$ are $(0.1594$, $0.2341)$ and $(0.1883,0.2392)$, respectively. The best forecasting ability of the DSAEF_LTP model in the training samples experiment has been improved with the introduction of the TC intensity for both precipitation

TABLE 3. List of training samples and independent samples for tropical cyclones.

\begin{tabular}{cc}
\hline \hline Sample classification & \multicolumn{1}{c}{ Names of tropical cyclone } \\
\hline Training samples & 2012: Doksuri, Kai-Tak, Son-Tinh \\
(13 tropical cyclones) & 2013: Rumbia, Soulik, Jebi, Utor, Usagi, \\
& Wutip, Haiyan \\
& 2014: Rammasun, Matmo, Kalmaegi \\
Independent samples & 2015: Noul, Linfa, Mujigae \\
(8 tropical cyclones) & 2016: Mirinae, Nida, Aere, Sarika, Haima \\
\hline
\end{tabular}



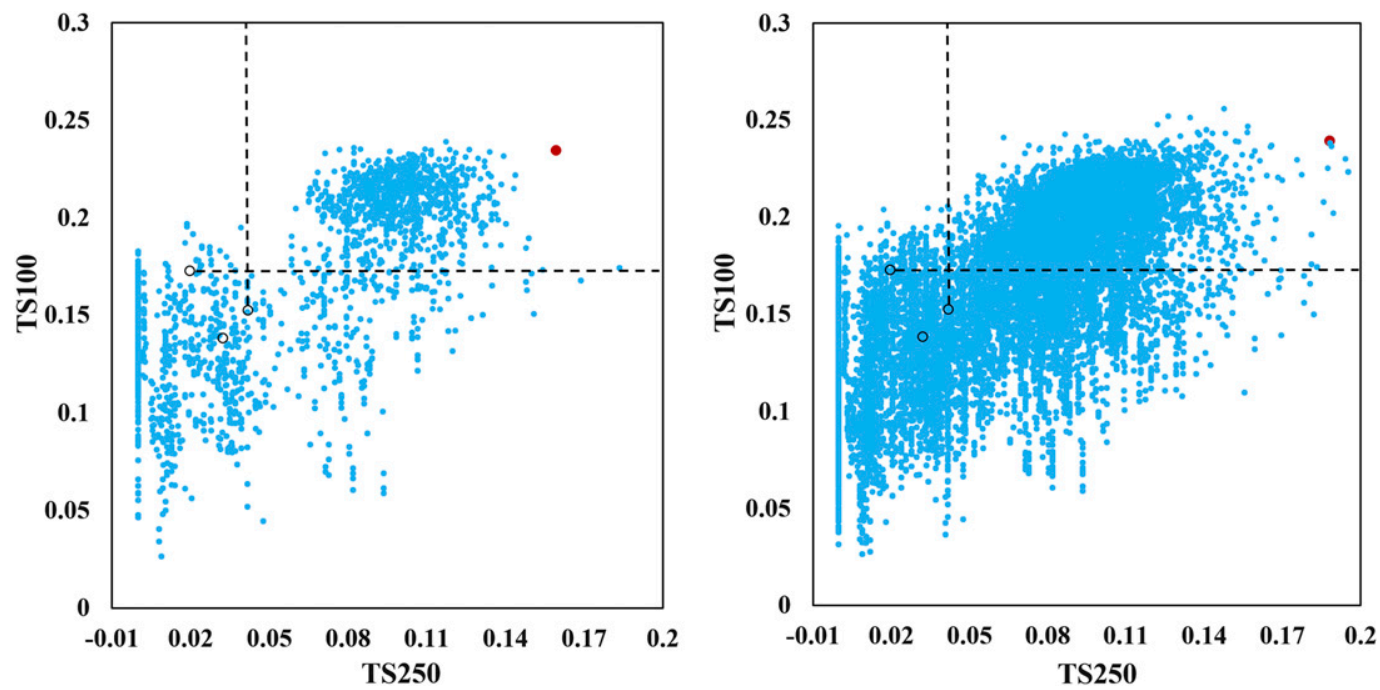

FIG. 2. Scatterplots of average threat scores for the training samples experiment for two thresholds of accumulated precipitation (accumulated precipitation $\geq 250$ and $\geq 100 \mathrm{~mm}$ ). The blue dots indicate the different schemes of the DSAEF_LTP model, the open circles denote the threat scores of the three NWP models (ECMWF, GFS, and T639), and the red dots are the best forecasting scheme of the DSAEF_LTP model. The dots in the first quadrant of the two intersecting dashed lines are the schemes with threat scores greater than the NWP models.

(a) DSAEF_LTP-2 model and (b) DSAEF_LTP-3 model.

thresholds. Table 2 shows the best forecasting scheme parameters of the DSAEF_LTP-3 model.

The independent samples experiment is conducted and the forecasting capability analyzed to test the performance of the DSAEF_LTP model in real prediction scenarios. Figure 3 compares the average threat score of the DSAEF_LTP-2, DSAEF_LTP-3, and the three NWP models. The average TS100 values of the DSAEF_LTP-2 and DSAEF_LTP-3 models are 0.1965 and 0.2413 , respectively. The prediction ability significantly improved when the intensity was introduced into the DSAEF_LTP model. At this precipitation threshold, the best performing of the three NWP models is the ECMWF model (threat score 0.2283), which has a lower score than the DSAEF_LTP-3 model. When the accumulated precipitation is $\geq 250 \mathrm{~mm}$, the average threat score decreases significantly. The TS250 values of the three NWP models are all equal to zero. The average TS250 value of the DSAEF_LTP-2 (DSAEF_LTP-3) model is 0.0493 (0.027). The result of the TS250 + TS100 shows that the performance of the DSAEF_LTP-3 model is better than that of the DSAEF_LTP-2 model and the three NWP models, although the DSAEF_LTP-2 model forecasts better than the DSAEF_LTP-3 model at TS250. Therefore, in terms of threat score the forecasting ability of the DSAEF_LTP model has been improved after the introduction of the TC intensity and it performs better than the three NWP models in the independent samples experiment.
Figure 4 shows the average bias score of the training and independent samples under the best scheme. From the training sample experiment (Fig. 4a), it can be seen that the BS250 (the bias score of accumulated precipitation $\geq 250 \mathrm{~mm}$ ) and BS100 (the bias score of accumulated precipitation $\geq 100 \mathrm{~mm}$ ) of the three NWP models are all less than 1 , which means that the area of misses is greater than that of false alarms. For the DSAEF_LTP model, both BS250 and BS100 are greater than 1, indicating the area of false alarms is greater than that of misses. In addition, among the three NWP models, the best values (closest to 1) of BS250 and BS100 are 0.2055 (T639) and 0.3 (GFS), respectively. And among the two DSAEF_LTP models, the two best values are 1.5345 and 1.3352 , both from the DSAEF_LTP-3 model. For the independent samples (Fig. 4b), the BS250 of the three NWP models and the two DSAEF_LTP models show similar characteristics to those in the training samples. However, for the BS100, two NWP models have bias greater than 1 , with the values of ECMWF and T639 being closer to 1 than those of the two DSAEF_LTP models.

The ability of the DSAEF_LTP-2 and DSAEF_LTP-3 models to forecast the accumulated precipitation $\geq$ $250 \mathrm{~mm}$, is presented in Fig. 5, which shows the TS250 of all 21 target TCs, from the three NWP models and the two DSAEF_LTP models. Some of the TCs in Fig. 5 have no threat score value, indicating that accumulated precipitation $\geq 250 \mathrm{~mm}$ was neither observed (eleven 


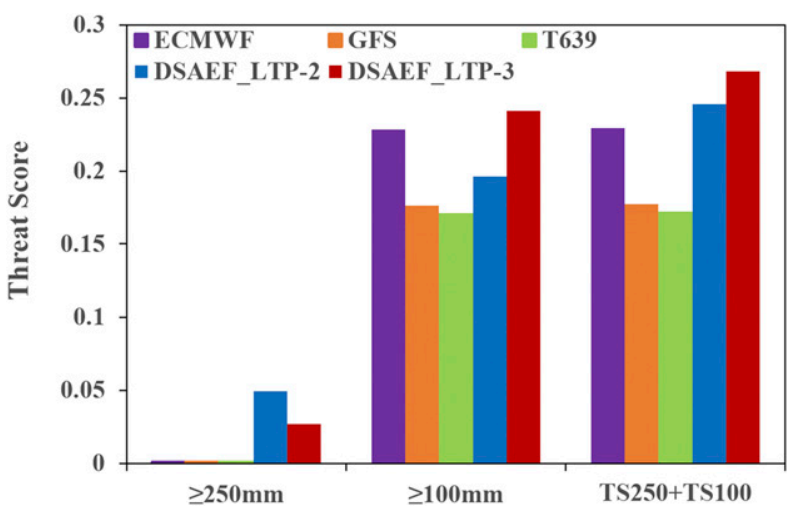

FIG. 3. Comparison of threat scores from different models (ECMWF, GFS, T639, DSAEF_LTP-2, and DSAEF_LTP-3) for independent samples.

target TCs have accumulated precipitation $<250 \mathrm{~mm}$ ) nor predicted for these TCs. There are 11 target TCs with no TS250 value for the ECMWF and GFS models, 10 for the T639 model, 3 for the DSAEF_LTP-2 model, and 6 for the DSAEF_LTP-3 model. The DSAEF_LTP model has more false alarms than the three NWP models. However, with the introduction of the TC intensity, this phenomenon decreases slightly. For the other 10 target TCs with observed accumulated precipitation $\geq 250 \mathrm{~mm}$, there are 7 TCs with TS250 greater than 0 for the DSAEF_LTP-3 model, 8 for the DSAEF_LTP-2 model, 1 each for the ECMWF and T639 models, and 2 for the GFS model. In terms of numbers, the DSAEF_LTP-2 and DSAEF_LTP-3 models perform better than the three NWP models, which have almost no ability to forecast accumulated precipitation $\geq 250 \mathrm{~mm}$. In general, accumulated precipitation $\geq 250 \mathrm{~mm}$ is rarely predicted for TCs by the three NWP models, whereas the DSAEF_LTP model can forecast accumulated precipitation $\geq$ $250 \mathrm{~mm}$, but with more false alarms. The number of false alarms decreases with the introduction of the TC intensity index.

To further understand the performance of the DSAEF_LTP-3 model, the relationship between the threat score and the TC rainfall intensity is examined in Fig. 6, which shows the maximum accumulated precipitation (the largest value of all rain gauge stations for each TC) and the threat score for the 21 samples. The maximum accumulated precipitation of the TC increases from left to right. The accumulated precipitation of 11 TCs to the left of the dotted black line is $<250 \mathrm{~mm}$. For the 11 samples with no observed accumulation $\geq 250 \mathrm{~mm}$, six TCs $(1323,1506,1307,1306,1411$ and 1320) have no TS250, while the remaining five have a TS250 of 0 (1207, $1624,1510,1605$ and 1309), indicating the presence of false alarms. The average TS250 of the 10 target TCs with accumulated precipitation $\geq 250 \mathrm{~mm}$ is 0.1695 ; the highest is 0.5556 (1418) and the lowest is zero. The results are better for TS100 than for TS250. Only three TCs $(1506,1307$, and 1411) have a TS100 value of zero. The TS100 of the 21 target TCs shows an upward trend as the accumulated precipitation increases. The positive correlation coefficient between the TS100 and the accumulated precipitation of 21 samples is 0.5159 , which passed the 0.05 significance level test. This means that the greater the accumulated precipitation of $\mathrm{TC}$, the more accurate the prediction of DSAEF_LTP-3 model (for TS100).

The relationship between the threat score and the intensity of the TC also has been analyzed. Figure 7 shows the intensity of the 21 target TCs at the forecasting time and the threat score under the best forecasting scheme of the DSAEF_LTP-3 model. The intensity of the target TCs increases from left to right. The ordinate is the TC intensity (left axis) and threat score (right axis). From left to right, the target TCs are tropical storm, STS, typhoon, STY and superTY in the area bounded by the dotted green, blue, red and black
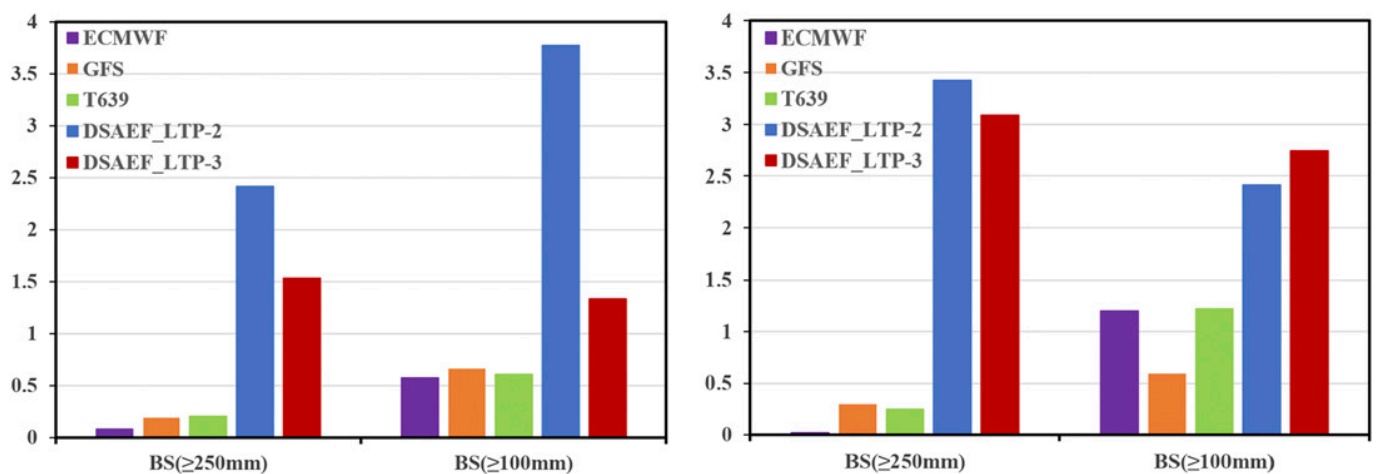

FIG. 4. Comparison of bias scores from different models (ECMWF, GFS, T639, DSAEF_LTP-2, and DSAEF_LTP-3) for (a) training and (b) independent samples. 


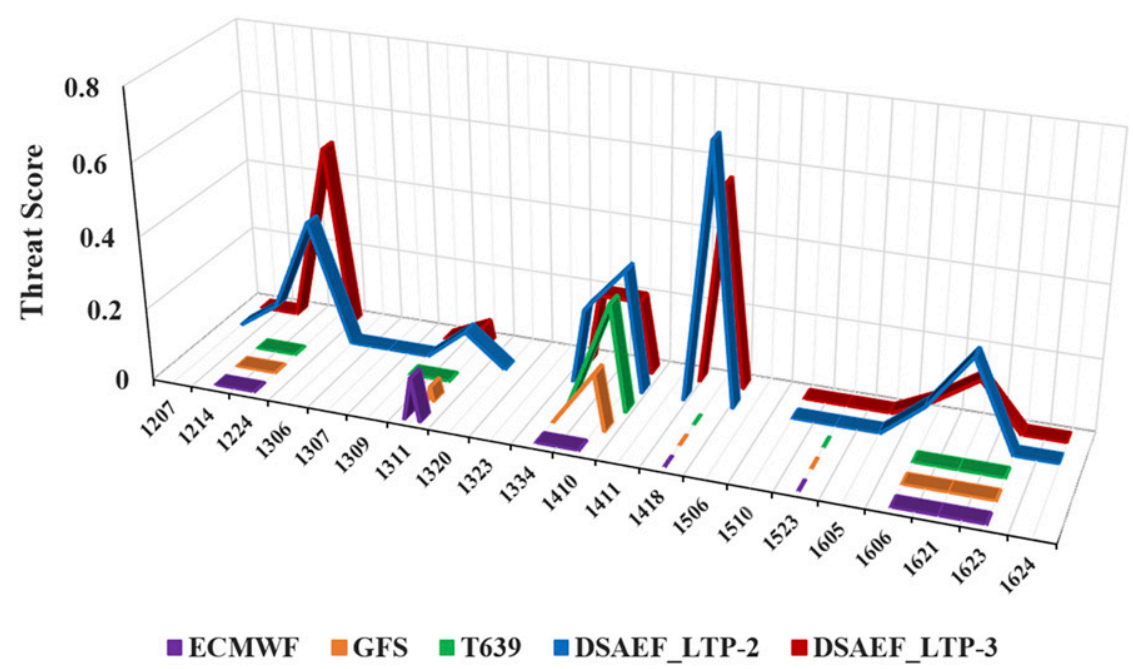

FIG. 5. Threat scores of 21 target tropical cyclones with accumulated precipitation $\geq 250 \mathrm{~mm}$ from different models (ECMWF, GFS, T639, DSAEF_LTP-2, and DSAEF_LTP-3).

lines and the two vertical axes. For the TS250, six TCs have no TS250 value, the same as in Fig. 6. The forecasting performance for target TCs with intensities of tropical storm and STS (10 TCs in total) is relatively weak. The average TS250 values of tropical storms and STS are 0.0667 and 0.1 , respectively. The reason for the poor performance is that the observed accumulated precipitation of 7 of the 10 TCs $(1309,1207,1605$, $1306,1411,1510$, and 1307$)$ is $<250 \mathrm{~mm}$, among which four $(1309,1207,1605$, and 1510) have false alarms.
The average TS250 of the other three TCs $(1621,1214$, and 1224) with accumulated precipitation $\geq 250 \mathrm{~mm}$ is 0.2111. In contrast, the forecasting performance for TCs that reach the typhoon and STY grades (10 TCs in total) is relatively good. The average TS250 values are 0.1528 and 0.1127 , respectively. Three TCs $(1323,1624$, and 1320) have accumulated precipitation $<250 \mathrm{~mm}$ and only one TC (1624) has a false alarm. Among the remaining seven TCs, five have TS250 greater than zero. The average TS250 of the seven TCs is 0.1517 . For TS100,

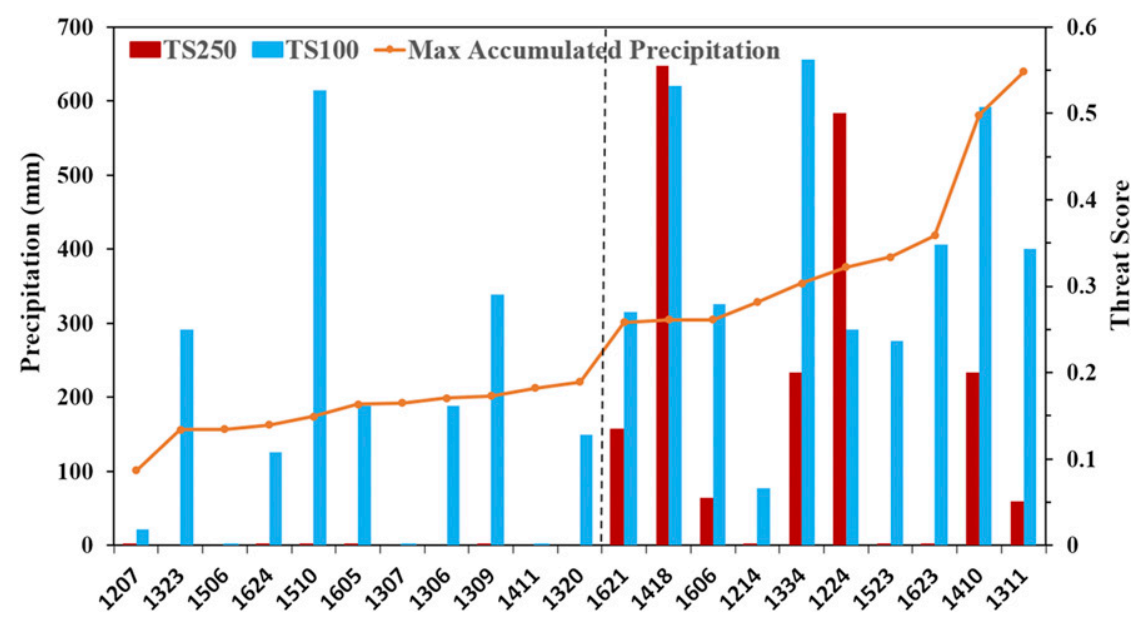

FIG. 6. Maximum accumulated precipitation and threat scores of 21 target tropical cyclones during 2012-16. The maximum accumulated precipitation is the largest value of all rain gauge stations for each tropical cyclone. The threat scores at different precipitation thresholds (TS250 and TS100) are from the best forecasting scheme of the DSAEF_LTP model, including the intensity of the tropical cyclone. The abscissa is the number of the target tropical cyclone (e.g., 1207 is the seventh tropical cyclone in 2012). The accumulated precipitation of the target tropical cyclone increases from left to right. The left-hand side of the black dashed line shows the tropical cyclones with accumulated precipitation $<250 \mathrm{~mm}$. 


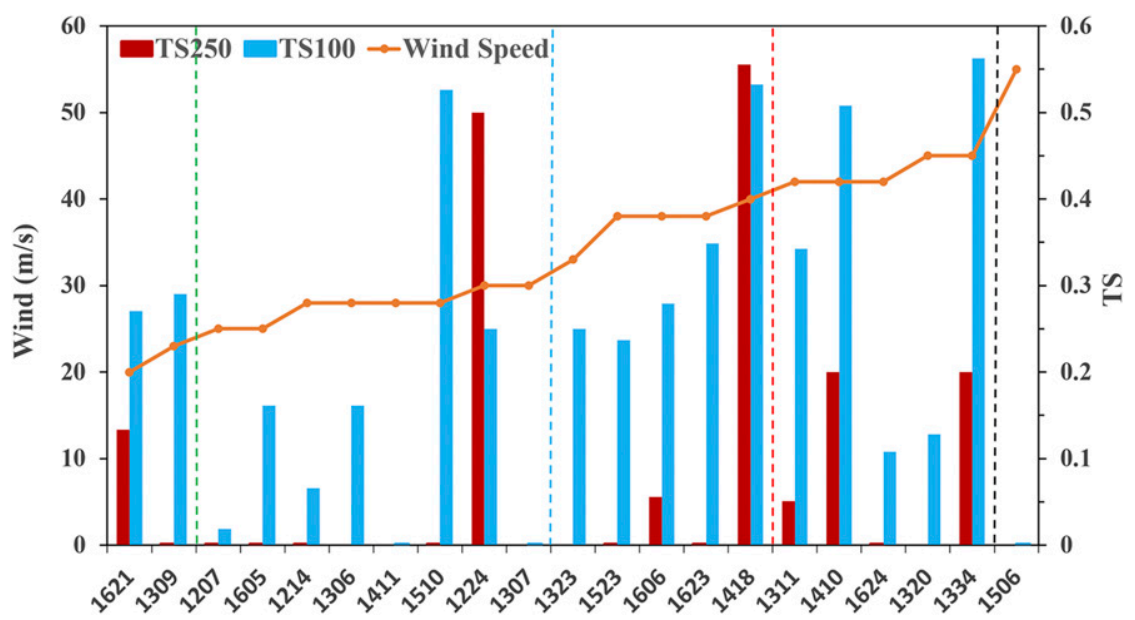

FIG. 7. Intensity and threat scores of 21 target tropical cyclones during 2012-16. The intensity is the wind speed at the initial forecast time for each tropical cyclone. The threat scores and abscissa are as in Fig. 5, and the intensity of target tropical cyclone increases from left to right. The intensity of the target tropical cyclones in the region is enclosed by green, blue, red, and black dashed lines, and the two vertical coordinate axes are tropical storms, severe tropical storms, typhoons, severe typhoons, and supertyphoons, respectively.

the average values of the tropical storm and STS grade target TCs are 0.2803 and 0.1479 , respectively. The target TCs at the typhoon and STY grades are relatively well predicted, with an average TS100 of 0.3294 and 0.3299 , respectively. The TS100 shows an increasing upward trend with intensity in the STS and typhoon grades of the target TCs. The correlation coefficient between TS100 and the wind speed is 0.5669 and passed the 0.05 significance test. This indicates that for the TCs in STS and typhoon grades, the stronger the TC intensity, the better the precipitation prediction performance of DSAEF_LTP-3 model. The decreasing trend of TS100 at intensity levels of STY and above (correlation coefficient between TS100 and wind speed -0.542 ) may be related to the intensity parameters of the best forecasting scheme. There are fewer historical TCs similar to the target TC when the screening criteria is the same grade and above because TCs in the STY and superTY grades are relatively rare.

To further illustrate the skill and the characteristics of the DSAEF_LTP-3 model, distributions of the observed and forecast accumulated precipitation for two target TCs are shown in Figs. 8 and 9. We select Kalmaegi (1418) with the largest sum of TS250 and TS100 and Doksuri (1207) with the smallest sum of TS250 and TS100 for further analysis.

Figures 8 and 9 show the distribution of the observed and forecasted accumulated precipitation of the two TCs, respectively. The observed heavy rainfall of Kalmaegi is mainly concentrated near its track (Fig. 8a). Accumulated precipitation $\geq 100 \mathrm{~mm}$ occurs on both sides of the track, while the center with precipitation $\geq 250 \mathrm{~mm}$ is located in the northern part of Hainan Island on the left-hand side of the track. The three NWP models are unable to predict precipitation $\geq 250 \mathrm{~mm}$, whereas the DSAEF_LTP-3 model is more accurate in forecasting heavy precipitation and its central location, with TS250 as high as 0.5556 (Figs. $8 \mathrm{~b}-\mathrm{e}$ ). The three NWP models have some forecasting capability for accumulated precipitation $\geq$ $100 \mathrm{~mm}$ (Figs. 8c-e). With this precipitation threshold, the ECMWF model $(\mathrm{TS} 100=0.603)$ gives the best prediction among the three models. The values of TS100 for the GFS and T639 models are 0.382 and 0.345 , respectively. The TS100 of the DSAEF_LTP-3 model is 0.5323 , second only to the ECMWF model (Fig. 8b).

In Fig. 9a, the observed accumulated precipitation of Doksuri in southern China is much weaker than that of Kalmaegi. Most rain gauge stations on the right-hand side of the track have precipitation $<10 \mathrm{~mm}$. On the left-hand side of TC track, the accumulated precipitation of several rain gauge stations exceeds $50 \mathrm{~mm}$ and there is only one rain gauge station exceeding $100 \mathrm{~mm}$. The amount of forecast precipitation in the three NWP models is also low (Figs. 9b-d). The precipitation of all stations forecasted by ECMWF is $<50 \mathrm{~mm}$. For the lefthand side of the TC track and near the landfall location, the GFS and T639 models predicted precipitation $\geq 50$ and $<100 \mathrm{~mm}$. The TS100 of all three NWP models is zero. There is a significant overprediction in the DSAEF_LTP-3 model (Fig. 9b). Most of the stations near and to the left of the TC track forecast precipitation $\geq$ $100 \mathrm{~mm}$, with maximum rainfall $\geq 400 \mathrm{~mm}$. These two 

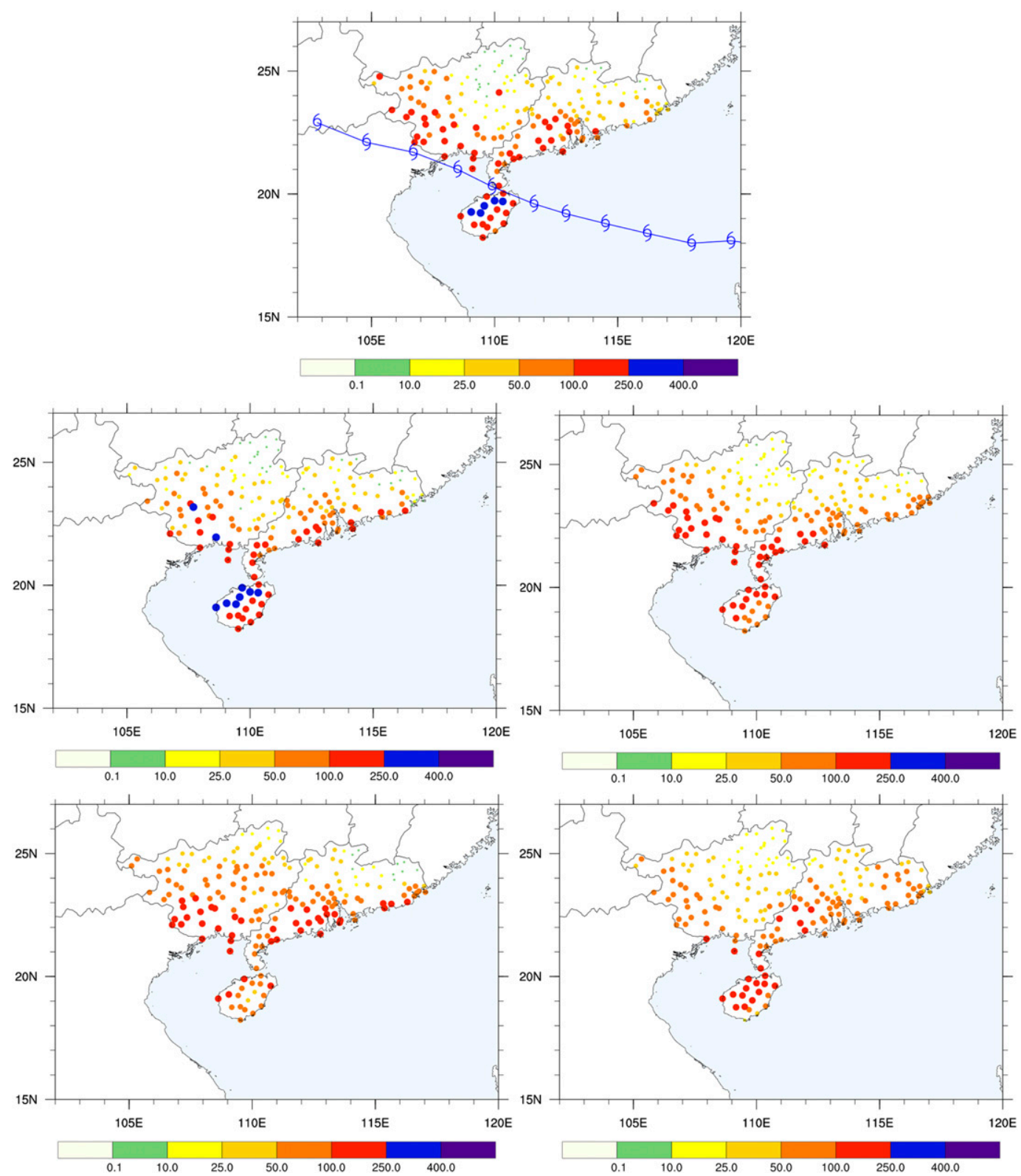

FIG. 8. Distribution of the accumulated precipitation ( $\mathrm{mm}$ ) associated with Kalmaegi (1418) from (a) rain gauge observations and predictions by (b) the DSAEF_LTP-3 model and the dynamic models (c) ECMWF, (d) GFS, and (e) T639. The blue line in (a) is the observed track of Kalmaegi (6-hourly positions).

examples are illustrative of the property that the DSAEF_LTP-3 model has more false alarms for TCs with weaker precipitation. Whereas, the DSAEF_LTP-3 model shows a clear advantage over the NWP models for larger accumulated precipitation situations.

\section{Summary and conclusions}

In this study, the TC intensity has been introduced as a third variable to construct the GIV of the DynamicalStatistical-Analog Ensemble Forecast model for Landfalling
Typhoon Precipitation (DSAEF_LTP). Forecast experiments have been conducted for accumulated precipitation for 21 target TCs in South China. The main results can be summarized as follows:

- TC intensity has been successfully introduced into the DSAEF_LTP model. The wind speed (2-min average maximum wind speed at 10-m height near the center of the TC) is used to indicate the intensity of the TC. To provide an index or model parameter, intensity information is classified in four categories and five 


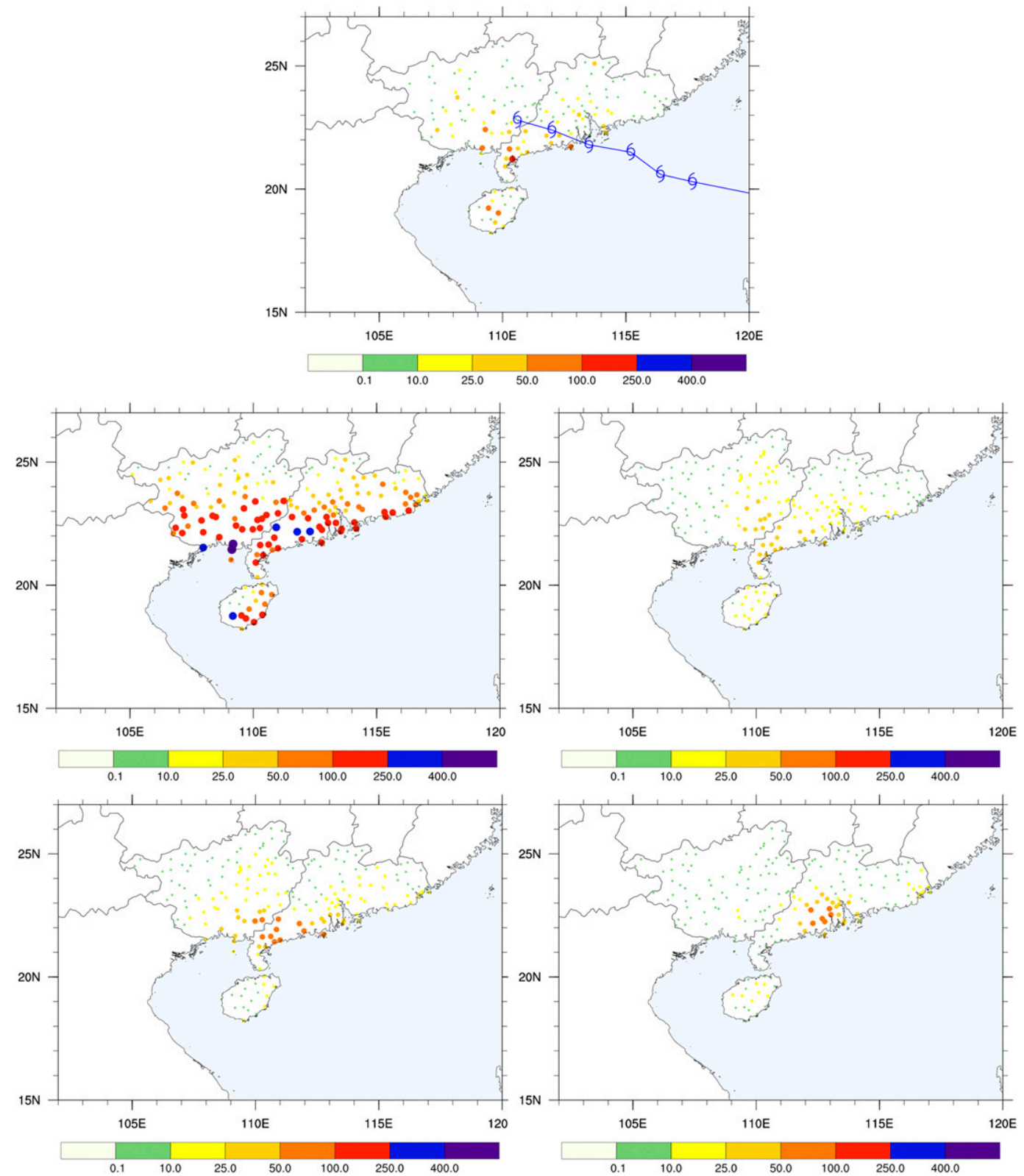

FIG. 9. Distribution of the accumulated precipitation $(\mathrm{mm})$ associated with Doksuri (1207) from (a) rain gauge observations and predictions by (b) the DSAEF_LTP-3 model and the dynamic models (c) ECMWF, (d) GFS, and (e) T639. The blue line in (a) is the observed track of Doksuri (6-hourly positions).

levels. The best parameter values of category and level are category 4 (the maximum observed intensity over all days that on land TC rainfall is observed) and level 2 (the same intensity grade and above). Thus in the choice of analogs, the best prediction is given by historic TCs with the same intensity grade and above as the target TC, using the maximum intensity in all rain days of the historic TC as a reference.

- After introducing the TC intensity, the DSAEF_LTP model has an improved forecasting ability for heavy rainfall and has certain advantages over the three NWP (ECMWF, GFS, and T639) models. The sums of the average threat scores (TS100 + TS250) for the revised DSAEF_LTP model in the training and independent experiments are 0.4275 and 0.2683 , respectively. Compared with the results before the introduction of the intensity of the TC, this is an improvement of $8.64 \%$ (training experiment) and $9.15 \%$ (independent experiment). In the independent experiment, the threat scores of accumulated precipitation $\geq 250$ and $\geq 100 \mathrm{~mm}$ for 
the DSAEF_LTP model (with intensity) are 0.027 and 0.2413 , respectively. Of the three NWP models, the ECMWF performs best, with threat scores of accumulated precipitation $\geq 250$ and $\geq 100 \mathrm{~mm}$ of 0 and 0.2283 , respectively. Thus the forecasting ability of the DSAEF_LTP model for accumulated precipitation $\geq$ $250 \mathrm{~mm}$ is superior to that of the NWP models and the forecasting ability for accumulated precipitation $\geq$ $100 \mathrm{~mm}$ is comparable with the NWP models. From the spatial distribution performance, the DSAEF_LTP model is more prone to false alarms while NWP models tend to more misses.

- The DSAEF_LTP model has a good predictive performance for high intensity TCs (typhoon and STY grades) and heavy accumulated precipitation observations. For an accumulated precipitation $\geq 250 \mathrm{~mm}$ $(\geq 100 \mathrm{~mm}$ ), the average threat scores of target TCs of typhoon and STY grades are 0.1528 and $0.1127(0.3294$ and 0.3299), respectively, higher than the values of 0.0667 and 0.1 (0.2803 and 0.1491), respectively, of the tropical storm and STS grades. When the intensity of the target TCs is below typhoon grade, the DSAEF_LTP model gives false alarms that result in the relatively low threat score at this precipitation threshold. This tendency decreases as the intensity of the target TCs increases beyond the typhoon and STY levels. The threat score for accumulated precipitation $\geq$ $100 \mathrm{~mm}$ increases as the intensity increases. In the range where the target TCs are at the level of STS and typhoon, the correlation coefficient between the threat score and intensity is 0.5667 and passes the 0.05 significance level test. The threat score of accumulated precipitation $\geq 100 \mathrm{~mm}$ is also closely related to the amount of accumulated precipitation. As the accumulated precipitation increases, the threat score of each target TC also shows an upward trend. The correlation coefficient over the 21 samples is 0.5159 and passes the 0.05 significance level test.

As discussed in the papers referred to in the Introduction (e.g., Jiang et al. 2018), TC intensity has a major influence on the area and amount of TC precipitation. The results above demonstrate that incorporating $\mathrm{TC}$ intensity as a variable in the choice of analog for the DSAEF_LTP model has improved the performance in predicting heavy precipitation. In our earlier paper that developed the theoretical basis of the model, we stated: "in the second step of constructing the generalized initial value, it is highly desirable to include all the physical variables that may influence LTP, including both TC's internal variables (e.g., intensity, size) and environmental variables (e.g., vertical wind shear, subtropical high, summer monsoon), many of which remain to be examined" (Ren et al. 2020). This paper has taken a further step in this direction through the inclusion of TC intensity as the third variable, after track and season. The experiments described here display that the method used to introduce TC intensity is effective, and suitable values for the intensity category and level have been obtained in the best scheme.

Meanwhile, the DSAEF_LTP model also shows an obvious weakness and tends to predict more false alarms than misses for TC accumulated precipitation. Further research investigations such as introducing more variables or more suitable ensemble parameters, are needed to solve this problem. In addition, experiments should be carried out for more target TCs (longer time range) in a larger area (such as the whole of China) to further improve the forecasting performance of the DSAEF_LTP model.

This study has made important progress in our research on combining dynamical forecasts with initial condition analogs from historical observations for the prediction of heavy rainfall events associated with landfalling typhoons.

Acknowledgments. This work was supported by the National Key R\&D Program of China (Grant 2018YFC1507703), the National Natural Science Foundation of China (Grant 41675042), and the Hainan Provincial Key R\&D Program of China (SQ2019KJHZ0028).

\section{REFERENCES}

Alvey, G. R., III, J. Zawislak, and E. Zipser, 2015: Precipitation properties observed during tropical cyclone intensity change. Mon. Wea. Rev., 143, 4476-4492, https://doi.org/10.1175/ MWR-D-15-0065.1.

Barnes, C. E., and G. M. Barnes, 2014: Eye and eyewall traits as determined with the NOAA WP-3D lower-fuselage radar. Mon. Wea. Rev., 142, 3393-3417, https://doi.org/10.1175/ MWR-D-13-00375.1.

Cecil, D. J., 2007: Satellite-derived rain rates in vertically sheared tropical cyclones. Geophys. Res. Lett., 34, L02811, https:// doi.org/10.1029/2006GL027942.

Chan, J. C., K. S. Liu, S. E. Ching, and E. S. Lai, 2004: Asymmetric distribution of convection associated with tropical cyclones making landfall along the South China coast. Mon. Wea. Rev., 132, 2410-2420, https://doi.org/10.1175/1520-0493(2004) 132<2410:ADOCAW >2.0.CO;2.

Chang, C. P., Y. Lei, C. Sui, X. Lin, and F. Ren, 2012: Tropical cyclone and extreme rainfall trends in East Asian summer monsoon since mid-20th century. Geophys. Res. Lett., 39, L18702, https://doi.org/10.1029/2012GL052945.

Chen, L. S., 2010: Tropical meteorological calamities and its research evalution (in Chinese). Meteor. Mon., 40, 3-10.

- and Y. L. Xu, 2017: Summary of typhoon torrential rain in China (in Chinese). Meteor. Environ. Sci., 40, 8.

_, Y. Li, and Z. Q. Cheng, 2010: An overview of research and forecasting on rainfall associated with landfalling tropical 
cyclones. Adv. Atmos. Sci., 27, 967-976, https://doi.org/ 10.1007/s00376-010-8171-y.

Chen, S. S., J. A. Knaff, and F. D. Marks, 2006: Effects of vertical wind shear and storm motion on tropical cyclone rainfall asymmetries deduced from TRMM. Mon. Wea. Rev., 134, 3190-3208, https://doi.org/10.1175/MWR3245.1.

DiMego, G. J., and L. F. Bosart, 1982: The transformation of tropical storm agnes into an extratropical cyclone. Part II: Moisture, vorticity and kinetic energy budgets. Mon. Wea. Rev., 110, 412-433, https://doi.org/10.1175/1520-0493(1982) $110<0412$ :TTOTSA $>2.0$. CO;2.

Dong, M. Y., L. S. Chen, P. Q. Zheng, and J. S. Pan, 2009: Research progress on abrupt intensification of heavy rainfall and super heavy rainfall associated with landfalling tropical cyclones (in Chinese). J. Trop. Meteor., 25, 495-502.

Emanuel, K., 2017: Assessing the present and future probability of Hurricane Harvey's rainfall. Proc. Natl. Acad. Sci. USA, 114, 12 681-12 684, https://doi.org/10.1073/pnas.1716222114.

Gao, S. T., L. K. Ran, N. Li, and X. Zhang, 2013: The "ensemble dynamic factors" approach to predict rainstorm (in Chinese). Torrential Rain Disasters, 32, 289-302.

Harnos, S. D., and S. W. Nesbitt, 2016: Varied pathways for simulated tropical cyclone rapid intensification. Part I: Precipitation and environment. Quart. J. Roy. Meteor. Soc., 142, 1816-1831, https://doi.org/10.1002/qj.2780.

Huang, Y., L. Jin, H. S. Zhao, and X. Y. Huang, 2018: Fuzzy neural network and LLE algorithm for forecasting precipitation in tropical cyclones: Comparisons with interpolation method by ECMWF and stepwise regression method. Nat. Hazards, 91, 201-220, https://doi.org/10.1007/s11069-0173122-x.

Jiang, H., and E. M. Ramirez, 2013: Necessary conditions for tropical cyclone rapid intensification as derived from 11 years of TRMM data. J. Climate, 26, 6459-6470, https://doi.org/ 10.1175/JCLI-D-12-00432.1.

Jiang, X., F. Ren, Y. Li, W. Qiu, Z. Ma, and Q. Cai, 2018: Characteristics and preliminary causes of tropical cyclone extreme rainfall events over Hainan Island. Adv. Atmos. Sci., 35, 580-591, https://doi.org/10.1007/s00376-017-7051-0.

Kieper, E. M., and H. Jiang, 2012: Predicting tropical cyclone rapid intensification using the $37 \mathrm{GHz}$ ring pattern identified from passive microwave measurements. Geophys. Res. Lett., 39, L13804, https://doi:10.1029/2012GL052115.

Klotzbach, P. J., C. J. Schreck III, J. M. Collins, M. M. Bell, E. S Blake, and D. Roache, 2018: The extremely active 2017 North Atlantic hurricane season. Mon. Wea. Rev., 146, 3425-3443, https://doi.org/10.1175/MWR-D-18-0078.1.

Li, Q. L., H. P. Lan, Z. L. Chen, C. Y. Cao, C. Li, and X. B. Wang, 2015: An operational statistical scheme for tropical cyclone induced rainfall forecast. J. Trop. Meteor., 21, 101-110.

Lin, X. H., W. Wu, and M. Han, 2016: Cause comparison analysis of different fallen area of heavy rain caused by typhoon landing in northeast Fujian (in Chinese). J. Nat. Disasters, 25, 45-55.

Liu, K. S., J. C. L. Chan, W. C. Cheng, S. L. Tai, and P. W. Wong, 2007: Distribution of convection associated with tropical cyclones making landfall along the South China coast. Meteor. Atmos. Phys., 97, 57-68, https://doi.org/10.1007/s00703-0060244-1.

Lonfat, M., F. D. Marks, and S. S. Chen, 2004: Precipitation distribution in tropical cyclones using the Tropical Rainfall Measuring Mission (TRMM) Microwave Imager: A global perspective. Mon. Wea. Rev., 132, 1645-1660, https://doi.org/ 10.1175/1520-0493(2004)132<1645:PDITCU>2.0.CO;2.
Lu, G., and D. Wong, 2008: An adaptive inverse-distance weighting spatial interpolation technique. Comput. Geosci., 34, 10441055, https://doi.org/10.1016/j.cageo.2007.07.010.

Luo, Y., M. Wu, F. Ren, L. Jian, and W. Wong, 2016: Synoptic situations of extreme hourly precipitation over China. J. Climate, 29, 8703-8719, https://doi.org/10.1175/JCLI-D-16-0057.1.

Marchok, T., R. Rogers, and R. Tuleya, 2007: Validation schemes for tropical cyclone quantitative precipitation forecasts: Evaluation of operational models for U.S. landfall cases. Wea. Forecasting, 22, 726-746, https://doi.org/10.1175/WAF1024.1.

McBride, J. L., and E. E. Ebert, 2000: Verification of quantitative precipitation forecasts from operational numerical weather prediction models over Australia. Wea. Forecasting, 15, 103-121, https://doi.org/10.1175/1520-0434(2000)015<0103: VOQPFF $>2.0 . \mathrm{CO} ; 2$.

Meng, W., and Y. Wang, 2016: A diagnostic study on heavy rainfall induced by Typhoon Utor (2013) in South China: 1. Rainfall asymmetry at landfall. J. Geophys. Res. Atmos., 121, $12781-$ 12 802, https://doi.org/10.1002/2015JD024646.

Qiu, W., F. Ren, L. Wu, Y. Xu, L. Chen, and C. Ding, 2019: Characteristics of tropical cyclone extreme precipitation and its preliminary causes in Southeast China. Meteor. Atmos. Phys., 131, 613-626, https://doi.org/10.1007/s00703018-0594-5.

Rappaport, E. N., 2000: Loss of life in the United States associated with recent Atlantic tropical cyclones. Bull. Amer. Meteor. Soc., 81, 2065-2074, https://doi.org/10.1175/1520-0477(2000) 081<2065:LOLITU>2.3.CO;2.

Ren, F., B. Gleason, and D. Easterling, 2001: A numerical technique for partitioning cyclone tropical precipitation (in Chinese). J. Trop. Meteor., 17, 308-313.

,-- , and,- 2002 : Typhoon impacts on China's precipitation during 1957-1996. Adv. Atmos. Sci., 19, 943-952, https:// doi.org/10.1007/s00376-002-0057-1.

, G. Wu, W. Dong, X. Wang, Y. Wang, W. Ai, and W. Li, 2006: Changes in tropical cyclone precipitation over China. Geophys. Res. Lett., 33, L20702, https://doi.org/10.1029/2006GL027951. , Y. Wang, X. Wang, and W. Li, 2007: Estimating tropical cyclone precipitation from station observations. Adv. Atmos. Sci., 24, 700-711, https://doi.org/10.1007/s00376-007-0700-y. , W. Qiu, C. Ding, X. Jiang, L. Wu, Y. Xu, and Y. Duan, 2018: An objective track similarity index and its preliminary application to predicting precipitation of landfalling tropical cyclones. Wea. Forecasting, 33, 1725-1742, https://doi.org/10.1175/ WAF-D-18-0007.1.

—, C. Ding, D. Zhang, D. Chen, H. Ren, and W. Qiu, 2020: A dynamical-statistical-analog ensemble forecast model: Theory and an application to heavy rainfall forecasts of landfalling tropical cyclones. Mon. Wea. Rev., 148, 1503-1517, https:// doi.org/10.1175/MWR-D-19-0174.1.

Shen, W., I. Ginis, and R. E. Tuleya, 2002: A numerical investigation of land surface water on landfalling hurricanes. J. Atmos. Sci., 59, 789-802, https://doi.org/10.1175/1520-0469(2002)059<0789: ANIOLS $>2.0 . \mathrm{CO} ; 2$.

Tuleya, R. E., M. Demaria, and R. J. Kuligowski, 2007: Evaluation of GFDL and simple statistical model rainfall forecasts for U.S. landfalling tropical storms. Wea. Forecasting, 22, 56-70, https://doi.org/10.1175/WAF972.1.

Wang, Y., X. Shen, and D. Chen, 2012: Verification of tropical cyclone rainfall predictions from CMA and JMA global models. J. Trop. Meteor., 18, 537-542.

Wei, C. C., 2012: RBF neural networks combined with principal component analysis applied to quantitative precipitation 
forecast for a reservoir watershed during typhoon periods. J. Hydrometeor., 13, 722-734, https://doi.org/10.1175/JHMD-11-03.1.

Wu, C., 2001: Numerical simulation of Typhoon Gladys (1994) and its interaction with Taiwan terrain using the GFDL hurricane model. Mon. Wea. Rev., 129, 1533-1549, https://doi.org/10.1175/ 1520-0493(2001)129<1533:NSOTGA > 2.0.CO;2.

, S. Chen, S. Lin, T. Yen, and T. Chen, 2013: Uncertainty and predictability of tropical cyclone rainfall based on ensemble simulations of Typhoon Sinlaku (2008). Mon. Wea. Rev., 141, 3517-3538, https://doi.org/10.1175/MWR-D-12-00282.1.

Xie, B., and F. Zhang, 2012: Impacts of typhoon track and island topography on the heavy rainfalls in Taiwan associated with Morakot (2009). Mon. Wea. Rev., 140, 3379-3394, https:// doi.org/10.1175/MWR-D-11-00240.1.

Xu, W., H. Jiang, and X. Kang, 2014: Rainfall asymmetries of tropical cyclones prior to, during, and after making landfall in South China and southeast United States. Atmos. Res., 139, 18-26, https://doi.org/10.1016/j.atmosres.2013.12.015.
Yu, Z., Y. Wang, and H. Xu, 2015: Observed rainfall asymmetry in tropical cyclones making landfall over China. J. Appl. Meteor. Climatol., 54, 117-136, https://doi.org/10.1175/ JAMC-D-13-0359.1.

,,--- N. Davidson, Y. Chen, Y. Chen, and H. Yu, 2017: On the relationship between intensity and rainfall distribution in tropical cyclones making landfall over China. J. Appl. Meteor. Climatol., 56, 2883-2901, https://doi.org/ 10.1175/JAMC-D-16-0334.1.

Zagrodnik, J. P., and H. Jiang, 2014: Rainfall, convection, and latent heating distributions in rapidly intensifying tropical cyclones. J. Atmos. Sci., 71, 2789-2809, https://doi.org/10.1175/ JAS-D-13-0314.1.

Zhang, Q., L. Wu, and Q. Liu, 2009: Tropical cyclone damages in China 1983-2006. Bull. Amer. Meteor. Soc., 90, 489-496, https://doi.org/10.1175/2008BAMS2631.1.

Zhang, Q. H., Q. Wei, and L. S. Chen, 2010: Research on the impact of typhoons landing in mainland China (in Chinese). Sci. Sin. Terrae, 40, 941-946. 